\title{
COMMON RISK FACTORS IN BANK STOCKS
}

\author{
A Dissertation \\ by \\ ARIEL MARCELO VIALE \\ Submitted to the Office of Graduate Studies of \\ Texas A\&M University \\ in partial fulfillment of the requirements for the degree of \\ DOCTOR OF PHILOSOPHY
}

May 2007

Major Subject: Finance 


\title{
COMMON RISK FACTORS IN BANK STOCKS
}

\author{
A Dissertation \\ by \\ ARIEL MARCELO VIALE \\ Submitted to the Office of Graduate Studies of \\ Texas A\&M University \\ in partial fulfillment of the requirements for the degree of \\ DOCTOR OF PHILOSOPHY
}

\begin{abstract}
Approved by:
Chair of Committee, James W. Kolari

Committee Members, Donald R. Fraser

Sorin Sorescu

Ekkehart Boehmer

Paula Hernandez Verme

Reza Langari

Head of Department, David Blackwell
\end{abstract}

May 2007

Major Subject: Finance 


\author{
ABSTRACT \\ Common Risk Factors in Bank Stocks. \\ (May 2007) \\ Ariel Marcelo Viale, B.A., Universidad Católica Andres Bello; \\ M.S., Texas A\&M University \\ Chair Advisory Committee: Dr. James W. Kolari
}

This dissertation provides evidence on the risk factors that are priced in bank equities. Alternative empirical models with precedent in the nonfinancial asset pricing literature are tested, including the single-factor Capital Asset Pricing Model (CAPM), three-factor Fama-French model, and Intertemporal Capital Asset Pricing Model (ICAPM).

The empirical results indicate that an unconditional two-factor Intertemporal Capital Asset Pricing Model (ICAPM) model, that includes the stock market excess return and shocks to the slope of the yield curve, is useful in explaining the cross-section of bank stock returns. I find no evidence, however, that firm specific factors, such as size and book-to-market ratios, are priced in bank stock returns. These results have a number of practical implications for event studies of banking firms, estimation of bank cost of capital and investment performance, as well as regulatory initiatives to utilize market discipline to evaluate bank risk under Basel II. 


\section{DEDICATION}

To the memory of my father Ariel Mario Viale and our long discussions about economics. To the memory of Alejandra, my mother Isabel, my children, Ariana, Ariel Enrique, and Patty, and my wife Mayra. 


\section{ACKNOWLEDGMENTS}

I am grateful to God who leads my work. Thanks also to many friends and colleagues, as well as the faculty and staff in the departments of Finance, Agricultural Economics, Economics, Control and Systems, Computer Science, and Mathematics, for making my time at Texas A\&M University a great academic experience. Finally, thanks to my wife and children for their encouragement, patience, and love. 


\section{TABLE OF CONTENTS}

ABSTRACT

I. INTRODUCTION .........................................................................

II. LITERATURE REVIEW ....................................................................

III. METHODOLOGICAL APPROACH ......................................................... 6

A. Data ....................................................................................... 6

B. Empirical Asset Pricing Models................................................... 7

C. Estimation Procedure .................................................................... 10

IV. EMPIRICAL RESULTS. ...................................................................... 12

A. Time Series Analysis.............................................................. 12

B. Cross-Sectional Analysis.............................................................. 16

C. Interpretation of Results............................................................ 18

D. Robustness Checks................................................................. 21

1. Estimation Bias .......................................................... 21

2. Fama-French Factors .................................................... 24

3. Conditional Tests of Long Run Predictability.................... 26

4. Other Conditional Tests ......................................................... 29

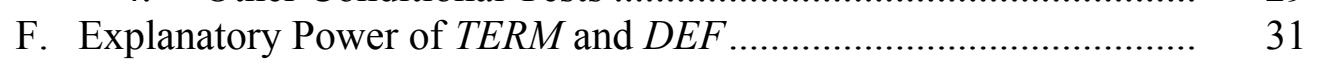

V. CONCLUSION .................................................................................. 34

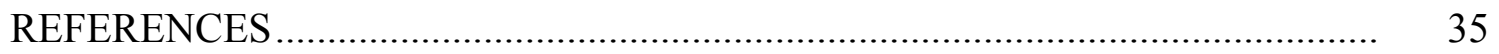

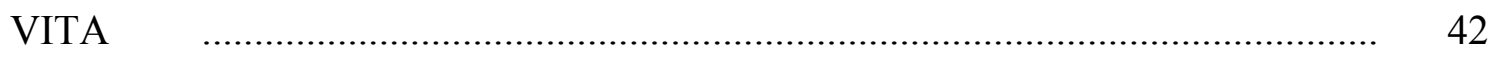




\section{LIST OF FIGURES}

FIGURE Page

1. Betas' Finite Sample Distributions …....................................................... 23 


\section{LIST OF TABLES}

TABLE Page

I Summary Statistics of Variables Included in the Unconditional Model..... 9

II Standard CAPM: Time-Series Regressions …………………………….... 13

III Three-Factor Fama-French Model: Time-Series Regressions ..................... 14

IV ICAPM Model: Time-Series Regressions................................................... 15

V Joint Tests of the CAPM, Three-Factor Fama-French, and ICAPM .......... 17

VI GAP and Loan Loss Ratios Across Banks Ranked by ME and BE/ME.... $\quad 20$

VII Bootstrap Simulation Analysis ................................................................ 22

VIII Incremental Explanatory Power of the Fama-French Risk Factors ............ 24

IX Relation Between Fama-French Factors and State Variables ..................... 25

X Univariate Predictors for the Maximum Sharpe Ratio.................................. 27

XI Cross-Section Tests in SDF Form - GMM Estimation Procedure - ........ 30

XII Contemporaneous Correlation Between TERM, DEF, GAP, and LOAN... 32 


\section{INTRODUCTION}

The Three Factor Asset Pricing Model of Fama and French $(1992,1993,1996)$ has seriously challenged the empirical validity of the Sharpe-Lintner-Mossin single-factor capital asset pricing model (CAPM). Empirical tests conducted by Fama and French demonstrated that firm size and the book-to-market ratio are the dominant factors in explaining the returns on a large sample of nonfinancial firms. In contrast, and contrary to the CAPM, market-wide factors (as proxied by the market beta) are unable to explain cross-sectional variations in the equity returns for their sample of nonfinancial firms. These results triggered numerous studies seeking to determine if this evidence could be explained by peculiarities of the data set, sample period, or other factors. For example, Kothari, Shanken, and Sloan (1995) and MacKinlay (1995) attributed much of these results to data snooping and survivorship bias, although Lakonishok, Shleifer, and Vishny (1994) found a strong relationship between the Fama and French variables and returns for a sample in which survivorship bias was mitigated. Other work by Fama and French (1998) has tested the three-factor model with non-U.S. equities and generally found results consistent with those reported for U. S. equities.

Fama and French excluded financial firms from their analysis because “... the high leverage that is normal for these firms probably does not have the same meaning as for nonfinancial firms, where high leverage more likely indicates financial distress." (1992, p. 429). Subsequently, Barber and Lyon (1997) comparatively examined the relationship between stock returns, firm size, and book-to-market ratios between NYSElisted financial and nonfinancial firms. They found no significant differences in the 
importance of these variables in financial firms from those in nonfinancial firms using data for the 1973-1994 period.

Identifying the common risk factors for financial firms is important both in terms of our understanding of the pricing of equities generally and for public policy purposes also. Regarding the former motivation, financial firms make up a substantial fraction of the domestic equity market. Indeed, they comprise almost $25 \%$ of the market value of all firms listed on NYSE in recent years. With respect to the latter motivation, extensive deregulation of financial and banking firms' asset and liability powers in the 1980s and 1990s has promulgated changes in regulatory policy to control the risk-taking behavior of these firms. In particular, long and substantial debates within the regulatory community over capital requirements have culminated in a new regulatory structure under Basel II that is focused on the use of market discipline as a major regulatory device. However, using market factors to evaluate and control risk-taking behavior by banks either by private market forces or by public regulators requires an understanding of the risk factors that are priced in security markets for these firms.

From the broad credit view of the monetary transmission mechanism, bank equity capital plays a crucial role in the economy determining the total amount of credit supply (see Bolton and Freixas (2006)). Hence, I provide empirical evidence on the common factors that are relevant in pricing bank equities using available data for U.S. banks over the 1986-2003 period. I test a multi-factor, ICAPM model and find that market and term risk factors are priced in bank stock returns. I also find that the risk captured by the term structure factor is highly correlated with bank accounting statement 
measures of bank spreads (i.e., short-term dollar-denominated interest rate gap). In contrast, I am unable to find evidence that firm-specific factors, such as size and bookto-market ratios, are priced in bank stock returns. Hence, the main result is that a twofactor model comprised of a market factor and innovations in the term structure provides a parsimonious approach for explaining the cross-section of average bank stock returns in the 1986-2003 period.

There are a number of important implications of our results. For example, consistent with market microstructure tests of banking stocks by Flannery, Kwan, and Nimalendran (2002), the conclusions suggest that bank stocks are not characteristically opaque in the sense that outside investors can value bank assets using publicly available information. As such, market discipline under Basel II appears to be a potentially feasible instrument to enhance bank supervision by regulatory agencies. The results also suggest that event studies in the banking industry should employ a two-factor model that includes market and term variables, rather than the previous convention of using market and interest rate variables (e.g., see Flannery and James (1984)). Finally, the results have relevance for computing the cost of capital for banking organizations, evaluating the investment performance of banks, and assessing management performance in maximizing shareholder wealth.

The next section briefly reviews related literature. Section III discusses the data and empirical approach. Section IV provides the empirical results, in addition to robustness checks. Section V concludes the dissertation. 


\section{LITERATURE REVIEW}

Previous empirical studies on the behavior of bank stock returns have found that an interest rate factor adds substantial explanatory power to the single factor CAPM (see e.g., Stone (1974), Lynge and Zumwalt (1980), Flannery (1981), Fogler, Kose and Tipton (1981), Flannery and James (1984), Yourougou (1990), Akella and Greenbaum (1992), Choi, Elyasiani and Kopecky (1992), Flannery, Hameed and Harjes (1997), Elyasiani and Mansur (1998), and Benink and Wolff (2000)). However as Giliberto (1985) shows, the relevance of these studies is limited because of a potential misspecification problem due to the use of orthogonalized residual factors obtained by regressing contemporaneously one factor on another factor.

Subsequently, a number of studies began using different conceptual and methodological approaches. For example, the results from principal components and canonical correlation analyses under the APT framework were not conclusive (Staikouras (2003)). One of the obstacles with this approach is that, if one analyzes different groups of test assets and finds two components in each group then it is impossible to know whether the identified components are the same across the groups. Bae (1990) experimented with both contemporaneous changes and surprises in market yields over various maturities. He concluded that sensitivities were more pronounced for surprises in yields than for expected changes in yields. Finally, Dinenis and Staikouras (1998) examined the effect of both expected and unanticipated interest rate changes in

the U.K. They concluded that surprises in interest rates had a statistically significant negative effect on bank stock returns. However, none of these studies performed formal 
asset-pricing tests to determine the empirical specification of an asset pricing model for bank stocks.

I assume that asset returns follow Merton's (1973) ICAPM in discrete-time with finite population moments up to the fourth order (i.e., strictly stationary and ergodic). ${ }^{1}$ Thus, population moments can be estimated using ordinary least squares (OLS), and asset-pricing implications can be conveniently deduced in terms of an unconditional model.

\footnotetext{
${ }^{1}$ See e.g., Campbell (1993, 1996), Li (1997), Hodrick, Ng and Sengmueller (1999), Chen (2003), Campbell and Vuolteenaho (2004), Brennan, Wang and Xia (2004), Petkova (2006), and Guo (2006).
} 


\section{METHODOLOGICAL APPROACH}

\section{A. Data}

I use all bank stocks available on CRSP with SIC codes 6020,6021, 6022, and 6029. Due to the lack of complete financial data from the Federal Reserve's Y-9C statements prior to 1986 , I begin the data series with 1986 CRSP stock returns and onemonth Treasury bill rates (collected monthly) and conclude with 2003 data. Bank stock excess returns are ranked on firm size (ME) and book-to-market (BE/ME). Size is measured by market capitalization at the end of June of year $t$. The book-to-market ratio is calculated by dividing the book value of common equity for the fiscal year ending in calendar time $t-1$ by the market value of equity at the end of December of $t-1$. I formed 25 portfolios from the intersections of five size and five book-to-market quintiles. The value-weighted monthly excess return on these 25 portfolios $R_{i, t}^{e}$ is the dependent variables in time-series and cross-sectional regressions.

Accounting information is taken both from the Y-9Cs and COMPUSTAT. Only commercial bank holding companies with ordinary common equity (as classified by CRSP) are included (i.e., ADRs, REITs, and units of beneficial interest are excluded). BE is the COMPUSTAT book value of stockholders' equity, plus balance-sheet deferred taxes and investment tax credit (if available), minus the book value of preferred stock. Depending on availability, I use the redemption, liquidation, or par value (in that order) to estimate the value of preferred stock. To be included in the sample, a firm must have CRSP stock prices for December of year $t-1$ and June of year $t$ and COMPUSTAT book common equity for year $t-1$. To avoid survival bias inherent in the way 
COMPUSTAT adds firms, I do not include firms until they have appeared on COMPUSTAT for two consecutive years. The resulting size quintiles comprise an average of 290 banks per year that represents the population of mid- and large-sized publicly traded banks in the U.S.

\section{B. Empirical Asset Pricing Models}

Since no previous studies empirically attempt formally to investigate the appropriate form of an asset-pricing model for bank stocks, I test a variety of alternative plausible models. First, I test the standard (single-factor) CAPM with the market risk factor $R_{M, t}^{e}$, which is calculated as the difference between the nominal return on the CRSP value-weighted stock market index and the one-month Treasury bill yield. I also tested Lettau and Ludvigson (2001) conditional CAPM. ${ }^{2}$

Second, following Fama and French (1993) I test a three-factor model with market, size, and value factors. The small-minus-big portfolio $S M B$, mimicking the size risk factor, is constructed as the monthly difference between the simple average of the returns on the three small-ME portfolios $(\mathrm{S} / \mathrm{L}, \mathrm{S} / \mathrm{M}$, and $\mathrm{S} / \mathrm{H})$ and the simple average of the returns on the three big-ME portfolios $(\mathrm{B} / \mathrm{L}, \mathrm{B} / \mathrm{M}$, and $\mathrm{B} / \mathrm{H})$, where $\mathrm{L}, \mathrm{M}$, and $\mathrm{H}$ denote the low, medium, and high BE/ME ratio portfolios respectively. The high-minuslow BE/ME portfolio $H M L$, mimicking the value risk factor, is constructed as the monthly difference between the simple average of the returns on the two high-BE/ME

\footnotetext{
${ }^{2}$ Because the adjusted $R^{2}$ values in the time-series regressions and the cross-sectional regression results were little changed, I don't include the results, but they are available upon request.
} 
portfolios $(\mathrm{S} / \mathrm{H}$ and $\mathrm{B} / \mathrm{H})$ and the simple average of the returns on the two low-BE/ME portfolios $(\mathrm{S} / \mathrm{L}$ and $\mathrm{B} / \mathrm{L})$.

Next, I test a general discrete time linear version of Merton's (1973) ICAPM. ${ }^{3}$ In this model the independent variables are the stock market excess return and innovations in a parsimonious set of state variables that help to forecast future market returns. The latter include innovations in $D I V, R F, T E R M$, and $D E F$, where $D I V$ is the market dividend yield of the CRSP value-weighted market index, $R F$ is the one-month Treasury bill yield, TERM is the difference between the yield on a portfolio of long-term government bonds (with more than 25 years maturity) and the one-month Treasury bill yield, and $D E F$ is the difference between the yield on a portfolio of long-term corporate bonds (Aaa/Baa) and the yield of a portfolio of long-term government bonds. As is common in the ICAPM literature, the innovations are obtained from a first-order vector autoregression (VAR) process. ${ }^{4}$ Note that the innovations are orthogonal to the excess market return with causality direction flowing from the state variable towards the market factor, so I can test whether unexpected changes in the state variables improves the explanatory power of the standard CAPM. I also test an alternative version of the

${ }^{3}$ The ICAPM can be written as:

$R_{i, t}=\alpha_{i}+\beta_{i, R_{M}^{e}} R_{M, t}^{e}+\sum_{k=1}^{K} \beta_{i, u^{k}} u_{t}^{k}+\varepsilon_{i, t}$, and $E\left[\mathbf{R}_{t+1}\right]=\boldsymbol{\beta}^{\prime} \boldsymbol{\lambda}=\boldsymbol{\lambda}_{R_{M}^{e}} \boldsymbol{\beta}_{R_{M}^{e}}+\sum_{k=1}^{K} \lambda_{u^{k}} \boldsymbol{\beta}_{u^{k}} \quad \forall i$

where $R_{M}^{e}$ is the stock market excess return, $u^{k}$ is the innovation in state variable $k$ that represents news about future market returns. The betas are the factor loadings at the end of period $t$ in the return-generating process. The risk premiums are the $\lambda$ coefficients in the cross-sectional regression.

${ }^{4}$ As shown by Campbell and Shiller (1988), any high order VAR can always be expressed as a first order (companion) VAR. One question that arises with this method is the "look-ahead bias" (i.e., as a result of using the full sample period to estimate the innovations). To address this problem I run a Monte Carlo analysis to assess potential size distortions, as well as univariate out-of-sample forecasting tests. 
Table I

Summary Statistics of Variables Included in the Unconditional Model

This table summarizes the set of variables used in the time series and cross-section regressions. The innovations are the unexpected component of each variable, obtained from a first-order vector autoregressive (VAR) process, where the excess market return is the first element in the VAR. All the state variables have been standardized. The sample period is from June 1986 to September 2003.

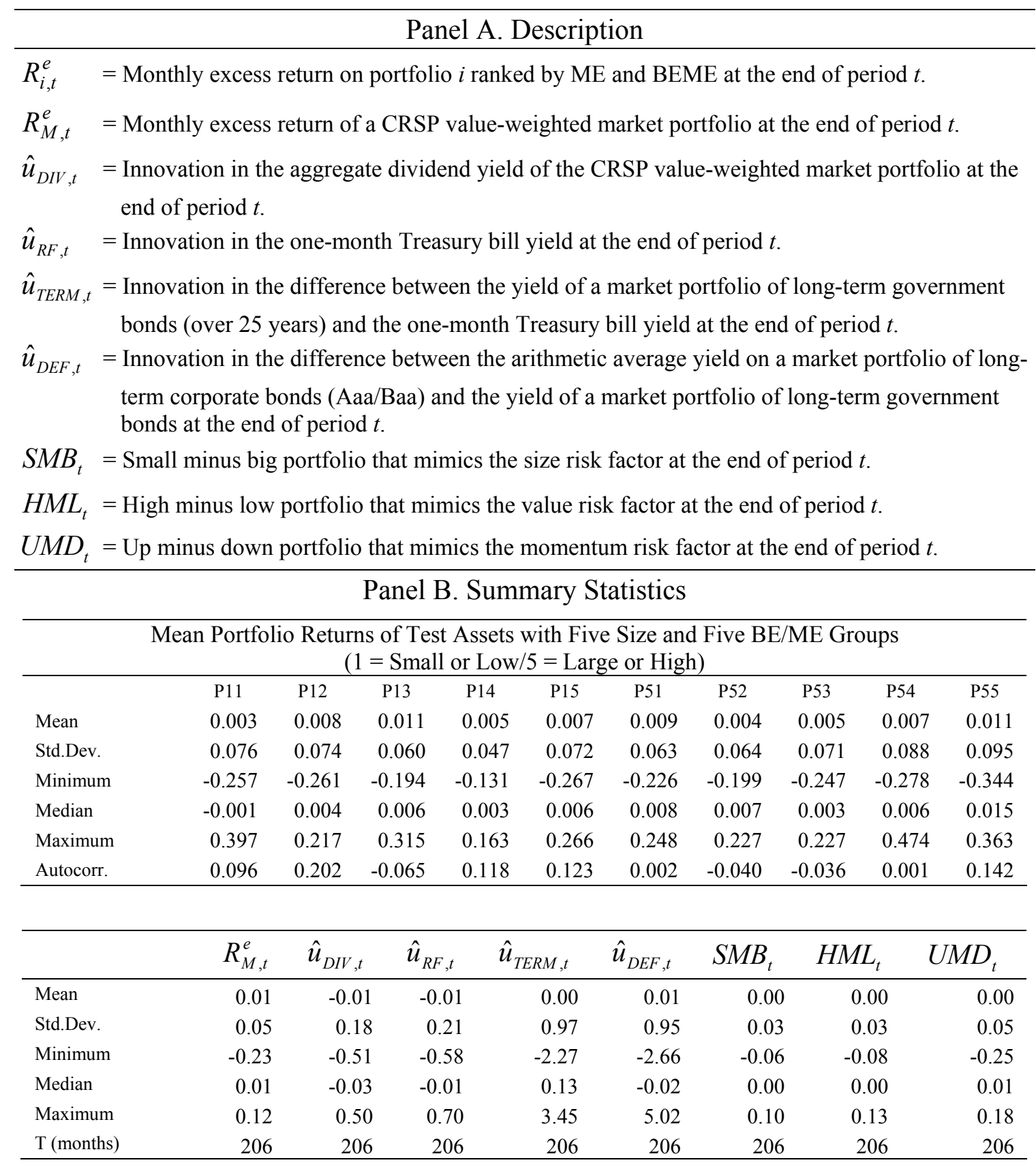


ICAPM model that follows from proposition 2 in the Appendix and includes as state variables innovations in $R F, T E R M$, and $D E F$.

Finally, based on work by Jegadeesh (1990), Jegadeesh and Titman (1993) and

others, I conduct additional tests with a momentum risk factor. The up-minus-down

portfolio UMD, mimicking the momentum risk factor is obtained from Kenneth

French's website. Table I provides a brief description and summary statistics of all the variables included in the analyses.

\section{Estimation Procedure}

Since not all risk factors are observable returns, I use the standard two-step regression approach of financial economics. In the first pass, I use two methods to obtain the beta estimates. First, following Lettau and Ludvigson (2001), I estimate full-sample ${ }^{5}$ betas using a seemingly unrelated (SUR) system that accounts for potential crosssectional heteroskedasticity and serial dependency. Although a SUR system with the same right-hand side regressors is equivalent to performing OLS, it has been shown, e.g., see Baltagi et al. (1989), that it is more efficient than OLS if the system is unbalanced (where the missing values are the result of the construction process to obtain the dependent variables). Second, using the Fama and MacBeth (1973) method, I

\footnotetext{
${ }^{5}$ Valkanov (2003) shows that the alternative approach of using standard statistical tests in direct long horizon regressions with overlapping data suffers from a small sample bias, i.e., the $R^{2}$ and $t$-statistics are not consistent and do not converge to well defined distributions respectively. Common perceptions in applied work is that out-of-sample prediction is more reliable than in-sample prediction and that in-sample tests are prone to uncovering spurious predictability. Inoue and Killian (2002) show that there is no econometric basis for such a perception. First, they demonstrate that in-sample and out-of-sample tests of predictability are asymptotically equally reliable under the null hypothesis of no predictability (i.e., no size distortions). Second, they show that for different in-sample and out-of-sample design choices, in-sample tests are more powerful than out-of-sample tests, even asymptotically (i.e., it is well known that they are more powerful in small samples).
} 
account for possible time-varying effects on the beta estimates (and any potential lookahead bias) by running time-series regressions with different rolling windows.

Because the betas are estimated parameters from first pass time-series regressions, their use in second pass cross-section regressions leads to the classical errors-in-variables (EIV) problem. I follow Shanken (1992) in correcting for this EIV problem. ${ }^{6}$ Since the innovations are also generated regressors that appear in the first-pass multiple time-series regressions, a second EIV problem arises. ${ }^{7}$ If the innovations are noisy proxies for the true surprises in the state vector, then the accuracy of the estimates of the factor loadings will depend on the direction of the bias. In the next section, I provide the results of a Monte Carlo experiment to assess the small sample distributions of the betas and risk premia.

Finally, I perform comparative time-series and cross-section analyses between the alternative asset pricing specifications. For this purpose, in the context of a timeseries analysis, I conduct the finite-sample $F$-test of Gibbons, Ross and Shanken (1989) (GRS). To assess the null hypothesis of zero mispricing in each model across test assets, I use the composite pricing error test $Q=T \boldsymbol{\alpha}^{\prime} \hat{\boldsymbol{\Sigma}}^{-1} \overline{\boldsymbol{\alpha}}$, where $T$ is the size of the sample period, $\overline{\boldsymbol{\alpha}}$ denotes the average residual vector in the cross-section regression, and $\hat{\boldsymbol{\Sigma}}$ is the variance-covariance matrix of the time-series residuals. This cross-sectional test has an asymptotic chi-squared distribution.

\footnotetext{
${ }^{6}$ Since Jagannathan and Wang (1998) contend that the Fama-MacBeth procedure does not produce biased estimators in the presence of heteroskedasticity, both unadjusted and adjusted statistics are reported.

${ }^{7}$ Pagan (1984) shows that if innovations proxy for the true unexpected changes in the state variables (using the appropriate econometric techniques), then OLS standard errors are correct.
} 


\section{EMPIRICAL RESULTS}

\section{A. Time Series Analysis}

This section reports the estimates of the risk factor loadings from first-pass timeseries regressions. ${ }^{8}$ Table II reports the results for the standard CAPM. The $F$-test shows that the 25 market betas are jointly significant at the 5\% significance level. More importantly, because the market factor is a return, the asset-pricing model predicts a restriction on the intercepts in the time-series regressions. In this case a time-series GRS test is identical to a two-step GLS cross-sectional test that includes the factor as a test asset (see Cochrane (2005, p. 244)). Note that the $R^{2}$ in the time-series regressions increase monotonically with size (i.e., from about $10 \%$ for small banks to about $35 \%$ for big banks). This is not surprising as shown by Fama and French (1992).

The results for the Fama-French three-factor model are presented in Table III. Because the model includes risk factors that are not returns, in this case the asset-pricing model does not predict a restriction on the intercepts in the time-series regressions. The adjusted $F$-tests imply that the 25 market betas are jointly significant at the $5 \%$ significance level. A weaker result is obtained for book-to-market sensitivities. Note that the adjusted $R^{2}$ values in the time-series regressions increase only marginally with respect to those obtained for the single-factor CAPM.

\footnotetext{
${ }^{8}$ The unreported results from a fixed-effects panel data model in beta form using GMM are quantitatively and qualitatively similar. These results are available upon request to the author.
} 
Table II

\section{Standard CAPM: Time-Series Regressions}

(Regression: $R_{i, t}^{e}=\alpha_{i}+\beta_{i, M} R_{M, t}^{e}+\varepsilon_{i, t}$ )

This table reports the factor loadings on the market factor $R_{M}^{e}$ computed from the first stage time series regressions for 25 portfolios sorted by size (ME) and book-to-market (BE/ME). Highlighted $t$-statistics denote statistical significance at the $5 \%$ level. The last column reports the adjusted $F$-statistic from the Wald tests, and their corresponding critical values. The adjusted $R^{2}$ values from each time series are reported below. The sample period is from July 1986 to September 2003.

\begin{tabular}{|c|c|c|c|c|c|c|c|c|c|c|c|c|}
\hline & Low & 2 & 3 & 4 & High & & Low & 2 & 3 & 4 & High & Adj. F \\
\hline & \multicolumn{5}{|c|}{$\hat{\alpha}$} & \multicolumn{7}{|c|}{$t_{\hat{\alpha}}$} \\
\hline Small & -0.0003 & 0.0045 & 0.0091 & 0.0045 & 0.0065 & & -0.0502 & 0.6955 & 2.1638 & 1.4772 & 1.5746 & \\
\hline 2 & 0.0120 & 0.0052 & 0.0023 & 0.0044 & 0.0017 & & 3.6668 & 1.5475 & 0.7857 & 1.4933 & 0.3187 & \\
\hline 3 & 0.0072 & 0.0080 & 0.0065 & 0.0104 & 0.0042 & & 2.6050 & 2.3238 & 2.3595 & 2.4475 & 0.6882 & \\
\hline 4 & 0.0079 & 0.0050 & 0.0049 & 0.0043 & 0.0101 & & 2.2194 & 1.7385 & 1.5626 & 1.0350 & 1.4813 & \\
\hline \multirow[t]{2}{*}{ Large } & 0.0056 & 0.0015 & 0.0041 & 0.0039 & 0.0064 & & 1.9370 & 0.4974 & 1.1347 & 0.8296 & 1.2622 & \\
\hline & \multicolumn{5}{|c|}{$\hat{\beta}_{M}$} & \multicolumn{7}{|c|}{$t_{\hat{\beta}_{M}}$} \\
\hline Small & 0.4444 & 0.4092 & 0.2773 & 0.2543 & 0.4596 & & 3.7136 & 3.2216 & 3.1797 & 3.8413 & 5.1495 & 16.52 \\
\hline 2 & 0.3604 & 0.5360 & 0.3377 & 0.5358 & 0.6309 & & 5.0086 & 7.5244 & 5.4345 & 8.3528 & 5.7927 & $>1.52$ \\
\hline 3 & 0.4995 & 0.1676 & 0.4467 & 0.4624 & 0.9725 & & 8.2009 & 2.2481 & 7.3718 & 4.9493 & 7.2720 & \\
\hline 4 & 0.9009 & 0.6069 & 0.5938 & 0.5594 & 0.7316 & & 11.6425 & 9.8309 & 8.8076 & 6.5067 & 5.0166 & \\
\hline \multirow[t]{8}{*}{ Large } & 0.8234 & 0.7557 & 0.6203 & 0.8989 & 1.0721 & & 13.0789 & 11.2566 & 8.1508 & 9.1702 & 9.5888 & \\
\hline & & & & Low & 2 & 3 & 4 & High & & & & \\
\hline & & & & \multicolumn{5}{|c|}{ Adj. $R^{2}$} & & & & \\
\hline & & & Small & 0.1079 & 0.1148 & 0.0887 & 0.1093 & 0.1398 & & & & \\
\hline & & & 2 & 0.1505 & 0.2878 & 0.1719 & 0.2820 & 0.2061 & & & & \\
\hline & & & 3 & 0.2847 & 0.0470 & 0.2752 & 0.1649 & 0.2790 & & & & \\
\hline & & & 4 & 0.4130 & 0.3755 & 0.3652 & 0.2859 & 0.1534 & & & & \\
\hline & & & Large & 0.4614 & 0.4233 & 0.3129 & 0.3651 & 0.3596 & & & & \\
\hline
\end{tabular}


Table III

Three-Factor Fama-French Model: Time-Series Regressions

(Regression: $R_{i, t}^{e}=\alpha_{i}+\beta_{i, M} R_{M, t}^{e}+\beta_{i, S M B_{t}} \hat{u}_{S M B, t}+\beta_{i, H M L_{t}} \hat{u}_{H M L, t}+\varepsilon_{i, t}$ )

This table reports loadings on the factors, $R_{M}^{e}, S M B$ and $H M L$ computed from the first stage time series regressions for 25 portfolios sorted by size (ME) and book-to-market (BE/ME). Highlighted $t$-statistics in black denote statistical significance at the $5 \%$ level. The last column reports the adjusted $F$-statistic from the Wald tests, and their corresponding critical values. The adjusted $R^{2}$ values from each time series are reported below. The sample period is from July 1986 to September 2003.

\begin{tabular}{|c|c|c|c|c|c|c|c|c|c|c|c|c|}
\hline & Low & 2 & 3 & 4 & High & & Low & 2 & 3 & 4 & High & Adj. F \\
\hline & \multicolumn{5}{|c|}{$\hat{\alpha}$} & \multicolumn{7}{|c|}{${ }^{t} \hat{\alpha}$} \\
\hline Small & 0.0011 & 0.0054 & 0.0090 & 0.0046 & 0.0063 & & 0.1876 & 0.8229 & 2.1102 & 1.5075 & 1.5599 & \\
\hline 2 & 0.0119 & 0.0063 & 0.0023 & 0.0044 & 0.0011 & & 3.7137 & 1.7704 & 0.8008 & 1.5012 & 0.2129 & \\
\hline 3 & 0.0074 & 0.0095 & 0.0065 & 0.0104 & 0.0026 & & 2.7016 & 2.8654 & 2.3454 & 2.4352 & 0.4342 & \\
\hline 4 & 0.0077 & 0.0047 & 0.0050 & 0.0039 & 0.0097 & & 2.1658 & 1.6413 & 1.5918 & 0.9169 & 1.4393 & \\
\hline \multirow[t]{2}{*}{ Large } & 0.0057 & 0.0013 & 0.0033 & 0.0056 & 0.0066 & & 1.9725 & 0.4232 & 0.9165 & 1.1803 & 1.3283 & \\
\hline & \multicolumn{5}{|c|}{$\hat{\beta}_{M}$} & \multicolumn{7}{|c|}{$t_{\hat{\beta}_{M}}$} \\
\hline Small & 0.4698 & 0.4335 & 0.2765 & 0.2680 & 0.4658 & & 3.9345 & 3.4006 & 3.1470 & 4.0635 & 5.3132 & 16.26 \\
\hline 2 & 0.3731 & 0.5627 & 0.3403 & 0.5405 & 0.6179 & & 5.2621 & 8.0529 & 5.4509 & 8.3569 & 5.7106 & $>1.52$ \\
\hline 3 & 0.5113 & 0.2054 & 0.4485 & 0.4670 & 0.9471 & & 8.4435 & 2.8608 & 7.3761 & 4.9687 & 7.1986 & \\
\hline 4 & 0.8929 & 0.5947 & 0.6039 & 0.5512 & 0.7051 & & 11.5176 & 9.6691 & 8.8988 & 6.4202 & 4.8278 & \\
\hline \multirow[t]{2}{*}{ Large } & 0.8320 & 0.7575 & 0.6040 & 0.9173 & 1.1111 & & 13.1604 & 11.3217 & 7.9276 & 9.3962 & 10.0834 & \\
\hline & \multicolumn{5}{|c|}{$\hat{\beta}_{S M B}$} & \multicolumn{7}{|c|}{${ }^{t} \hat{\beta}_{S M B}$} \\
\hline Small & -0.1305 & -0.1104 & 0.0204 & -0.0214 & 0.0464 & & -0.6238 & -0.4947 & 0.1360 & -0.1987 & 0.3264 & 1.12 \\
\hline 2 & -0.2885 & -0.1748 & -0.1430 & -0.0780 & 0.0512 & & -2.5399 & -1.5051 & -1.4194 & -0.7479 & 0.2697 & $<1.52$ \\
\hline 3 & -0.2071 & -0.0623 & -0.0531 & -0.1313 & -0.0024 & & -2.1339 & -0.5258 & -0.5391 & -0.8867 & -0.0106 & \\
\hline 4 & 0.0171 & 0.0160 & -0.0844 & -0.3274 & -0.4364 & & 0.1360 & 0.1597 & -0.7705 & -2.1936 & -1.8231 & \\
\hline \multirow[t]{2}{*}{ Large } & 0.0362 & 0.2173 & 0.0208 & 0.0129 & -0.0519 & & 0.3541 & 1.9700 & 0.1637 & 0.0791 & -0.2876 & \\
\hline & \multicolumn{5}{|c|}{$\hat{\beta}_{H M L}$} & \multicolumn{7}{|c|}{${ }^{t} \hat{\beta}_{H M L}$} \\
\hline Small & 0.4080 & -0.1691 & 0.0426 & 0.2868 & 0.4966 & & 1.8827 & -0.4819 & 0.2389 & 2.5667 & 3.1071 & 2.64 \\
\hline 2 & 0.3137 & 0.3963 & 0.1165 & 0.1175 & 0.2812 & & 2.5561 & 3.2457 & 1.0482 & 1.0192 & 1.2279 & $>1.52$ \\
\hline 3 & 0.1514 & 0.4724 & -0.0012 & 0.2189 & 0.2850 & & 1.4225 & 3.4752 & -0.0112 & 1.3125 & 1.3476 & \\
\hline 4 & -0.1980 & -0.1918 & 0.1193 & -0.1123 & -0.0393 & & -1.4230 & -1.7379 & 1.0422 & -0.6899 & -0.1530 & \\
\hline \multirow[t]{8}{*}{ Large } & 0.0442 & 0.0203 & -0.0319 & 0.5181 & 0.5737 & & 0.3896 & 0.1737 & -0.2122 & 2.5307 & 3.0920 & \\
\hline & & & & Low & 2 & 3 & 4 & High & & & & \\
\hline & & & & \multicolumn{5}{|c|}{ Adj. $R^{2}$} & & & & \\
\hline & & & Small & 0.1248 & 0.1068 & 0.0772 & 0.1330 & 0.1672 & & & & \\
\hline & & & 2 & 0.1863 & 0.3277 & 0.1711 & 0.2804 & 0.2001 & & & & \\
\hline & & & 3 & 0.2986 & 0.1040 & 0.2676 & 0.1654 & 0.2739 & & & & \\
\hline & & & 4 & 0.4106 & 0.3723 & 0.3649 & 0.2813 & 0.1434 & & & & \\
\hline & & & Large & 0.4613 & 0.4268 & 0.2975 & 0.3704 & 0.3888 & & & & \\
\hline
\end{tabular}


Table IV

ICAPM Model: Time-Series Regressions

(Regression: $R_{i, t}^{e}=\alpha_{i}+\beta_{i, M} R_{M, t}^{e}+\beta_{i, R F} \hat{u}_{R F, t}+\beta_{i, T E R M} \hat{u}_{T E R M, t}+\beta_{i, D E F} \hat{u}_{D E F, t}+\varepsilon_{i, t}$ )

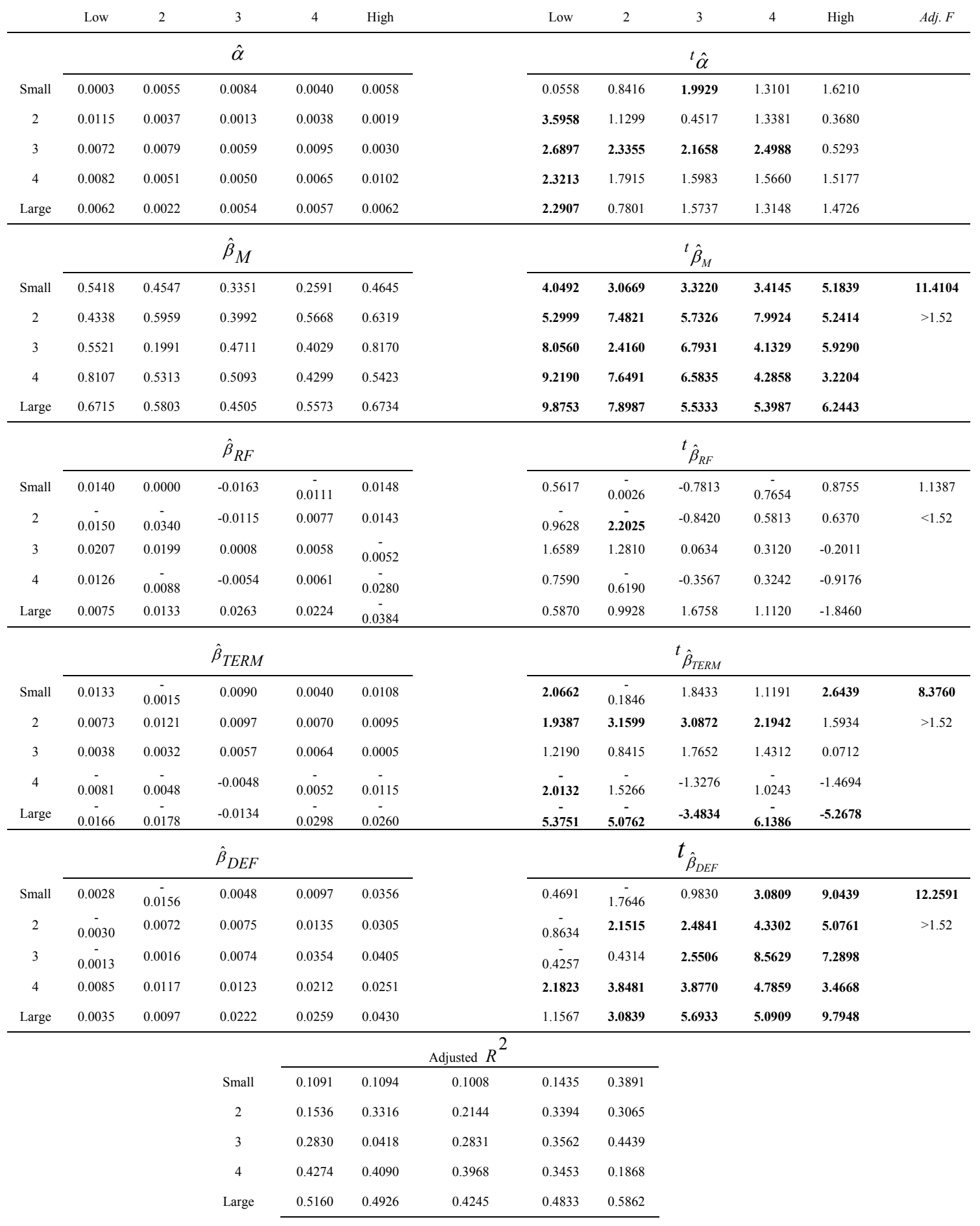


I run two different versions of the ICAPM model - namely, with and without innovations in the dividend yield factor. The results are quantitatively and qualitatively similar, and innovations in the dividend yield factor are not significant in both cases. Hence, Table IV reports only the estimates for the ICAPM model with $R_{M}^{e}, \hat{u}_{R F}, \hat{u}_{T E R M}$, and $\hat{u}_{D E F}$ as regressors. The results with dividend yields are available upon request to the author. The adjusted $F$-tests show that the 25 market, term, and default betas are jointly significant at the 5\% significance level. Fama and French (1993) also found that these variables are statistically significant for defaultable corporate bonds. Because the model includes risk factors that are not returns, again the asset-pricing model does not predict a restriction on the intercepts in the time-series regressions. Note that $R^{2}$ values increase significantly with respect to those obtained for the single factor CAPM, in addition to those for any of the other asset pricing models included in the analysis. This improvement is especially relevant for large banks (i.e., from about $35 \%$ to about $50 \%$ ).

\section{B. Cross-Sectional Analysis}

Panel A of Table V contains the results that correspond to the second-pass fullsample GLS cross-section regressions following Lettau and Ludvigson's (2001) method. The null hypothesis of zero mispricing cannot be rejected for the standard CAPM (i.e., validating the GRS time-series test), with an unadjusted $p$-value of $14.89 \%$ and (EIV) adjusted $p$-value of $7.32 \%$. The $t$-statistic reported in Panel A for the market factor risk premium is statistically significant under the (EIV) adjustment. The null hypothesis of zero mispricing is rejected for the three-factor Fama-French model, and the $t$-statistic for the market factor risk premium is statistically significant under the (EIV) adjustment. 
Table V

Joint Tests of the CAPM, Three-Factor Fama-French, and ICAPM

(Cross Section Regression: ${\overline{\mathbf{R}}-R_{f}}=\hat{\beta} \lambda+\boldsymbol{\alpha}$ )

This table reports the (second-stage) cross-sectional regression results under the standard version of the CAPM, three-factor Fama-French model, and the ICAPM. Panel A shows the results using a GLS full sample method. Panel B gives the results using the Fama and MacBeth (1973) rolling regression method. The sample means of the monthly portfolio excess returns are regressed on the betas without the intercept, such that the mispricing term is the residual, $\hat{\alpha}=\overline{\mathbf{R}-R}_{f}-\hat{\beta} \lambda$. A Wald test is then performed on the time series (first-stage) $\hat{\alpha}$ to test the joint significance of the mispricing term. The individual $t$-statistics and the variance-covariance matrix, $\sum$, are calculated using Shanken's correction. Highlighted values denote statistical significance at the 5\% level. The sample period is from July 1986 to September 2003.

\begin{tabular}{|c|c|c|c|c|c|c|c|c|}
\hline & \multirow{2}{*}{$\begin{array}{l}\text { CAPM } \\
\hat{\lambda} \\
R_{M}^{e} \\
\quad\end{array}$} & \multicolumn{3}{|c|}{ FF - Three Factor Model } & \multicolumn{4}{|c|}{ ICAPM } \\
\hline & & $\begin{array}{l}\hat{\lambda} \\
R_{M}^{e}\end{array}$ & $\hat{\lambda}_{\hat{u}}$ & $\stackrel{\hat{\lambda}}{\hat{u}}_{H M L}$ & $\begin{array}{l}\hat{\lambda} \\
R_{M}^{e}\end{array}$ & $\lambda_{\hat{u}}$ & $\lambda_{\hat{u}}$ & $\hat{\lambda}_{\hat{u}}$ \\
\hline Estimate & $1.10 \%$ & $0.94 \%$ & $-1.22 \%$ & $0.18 \%$ & $1.40 \%$ & $-4.45 \%$ & $1.68 \%$ & $-2.96 \%$ \\
\hline std. $t$-stat & 10.58 & 7.89 & -2.35 & 0.58 & 7.29 & -0.92 & 0.27 & -0.50 \\
\hline adj. t-stat & 9.51 & 7.19 & -1.96 & 0.56 & 6.39 & -0.82 & 0.26 & -0.49 \\
\hline $\begin{array}{l}\text { std. } \\
\alpha^{\prime} \Sigma^{-1} \alpha\end{array}$ & 31.17 & 34.92 & & & 29.90 & & & \\
\hline $\begin{array}{l}p \text {-value } \\
\text { adj. }\end{array}$ & $14.89 \%$ & $3.92 \%$ & & & $9.40 \%$ & & & \\
\hline$\hat{\alpha}^{\prime} \Sigma^{-1} \hat{\alpha}$ & 34.68 & 38.73 & & & 31.70 & & & \\
\hline p-value & $7.32 \%$ & $1.51 \%$ & & & $6.27 \%$ & & & \\
\hline
\end{tabular}

PANEL B: 1 Year Rolling Regressions $(N=194)$

\begin{tabular}{|c|c|c|c|c|c|c|c|c|}
\hline & \multirow{2}{*}{$\begin{array}{l}\text { CAPM } \\
\hat{\lambda} \\
\quad R^{e} \\
\quad M\end{array}$} & \multicolumn{3}{|c|}{ FF - Three Factor Model } & \multicolumn{4}{|c|}{ ICAPM } \\
\hline & & $\begin{array}{l}\hat{\lambda} \\
\quad R_{M}^{e}\end{array}$ & $\hat{\lambda}_{\hat{u}}$ & $\hat{\lambda}_{\hat{u}}$ & $\begin{array}{l}\hat{\lambda} \\
R_{M}^{e}\end{array}$ & $\lambda_{\hat{u}}$ & $\lambda_{\hat{u}}{ }_{\text {TERM }}$ & $\hat{\lambda}_{\hat{u}}$ \\
\hline Estimate & $0.85 \%$ & $1.00 \%$ & $-0.38 \%$ & $0.05 \%$ & $0.95 \%$ & $0.79 \%$ & $-15.67 \%$ & $4.14 \%$ \\
\hline $\begin{array}{l}\text { std. } \\
t \text {-stat }\end{array}$ & 2.16 & 2.29 & -1.97 & 0.32 & 2.40 & 0.35 & -2.46 & 0.63 \\
\hline $\begin{array}{l}\text { adj. } \\
t \text {-stat }\end{array}$ & 1.99 & 2.08 & -1.85 & 0.32 & 2.20 & 0.32 & -2.26 & 0.61 \\
\hline
\end{tabular}

The null hypothesis of zero mispricing cannot be rejected for the ICAPM, with an unadjusted $p$-value of $7.60 \%$ and (EIV) adjusted $p$-value of $5.00 \%$. The $t$-statistics reported in Panel A for the market risk premium are statistically significant with and without (EIV) adjustment. The fact that innovations do not appear to be priced cross- 
sectionally under this method may reflect an EIV problem biasing the results against statistical significance.

Panel B of Table V reports the results that correspond to the second-pass crosssectional regression using the Fama and MacBeth (1973) procedure. Only the results for 1-year rolling regressions are shown (i.e., 194 cross-section estimates) for comparative purposes with respect to the full-sample period procedure (i.e., one cross-sectional estimate). The unreported results with 3-and 5-year windows are qualitatively similar. The $t$-statistics reported in Panel B for the market risk premium in the standard CAPM, the three-factor Fama-French model, and the ICAPM are statistically significant under the (EIV) adjustment. The $t$-statistics for the Fama-French factors' risk premia are not statistically significant under the (EIV) adjustment. The $t$-statistics reported for the term factor risk premium in the ICAPM are statistically significant with and without the (EIV) adjustment. This confirms that time-varying effects in the factor loadings of innovations in TERM biased the full-sample results against its statistical significance as conjectured before.

\section{Interpretation of Results}

The empirical evidence supports the focus in the practitioner literature on the shape of the yield curve in explaining prospects for bank stocks. A steeper yield curve provides increased net income profit from the carry trade, which involves borrowing shorter-term funds at lower interest rates and investing these funds in longer-term loans and securities at higher interest rates (e.g., see Hanweck and Ryu (2005)). On the other hand, innovations on the slope of the yield curve are closely related with the real 
business cycle. The yield curve is steeper near the trough of the real business cycle (with negative shocks signaling a possible shift to good times) and relatively flat near the peak of the real business cycle (with positive shocks signaling a possible shift to bad times).

From an ICAPM perspective, the negative sign of the TERM premium implies that bank stocks constitute a hedge against future negative shocks to consumption growth. It is important in this regard to observe that, as shown in Table IV, the sensitivity coefficients for shocks in TERM vary across bank size quintiles. Smaller banks tend to have positive betas, whereas larger banks have negative betas. As such, positive contemporaneous shocks in TERM represent good news for smaller banks but bad news for larger banks. These results suggest that interest rate risk exposures of smaller and larger banks are quite different.

To assess these differences, I compute the banks' short-term interest rate gap ratios (defined as short-term assets minus short-term liabilities repriceable within one year and divided by total assets). Table VI shows the mean values of these gap ratios across size and book-to-market groups (in addition to the average values of the banks' loan loss ratios discussed below). The smallest banks had negative gaps (e.g., -0.043 on average for banks in the lowest size quintile across the five size quintiles) in sharp contrast to larger banks with positive gap ratios (e.g., 0.375 on average for banks in the largest size quintile). The $F$-statistic test for significant differences among average gaps ranked by size groups is highly significant. Mean gap ratios did not differ significantly across book-to-market groups. Note that positive short-term dollar gaps for bigger banks 
Table VI

Gap and Loan Loss Ratios Across Banks Ranked by ME and BE/ME

This table reports the mean values of gap and loan loss ratios for banks in different size and book-tomarket groups. Gap is defined as short-term assets minus short-term liabilities repriceable within one year divided by total assets. Loan loss is defined as net charge-offs for losses on loans (i.e., gross charge-offs minus recoveries) divided by the amount of total loans. $F$-statistics tests for the equality of means across $\mathrm{ME}$ and $\mathrm{BE} / \mathrm{ME}$ groups are reported. Values in black denote statistical significance at the $1 \%$ level.

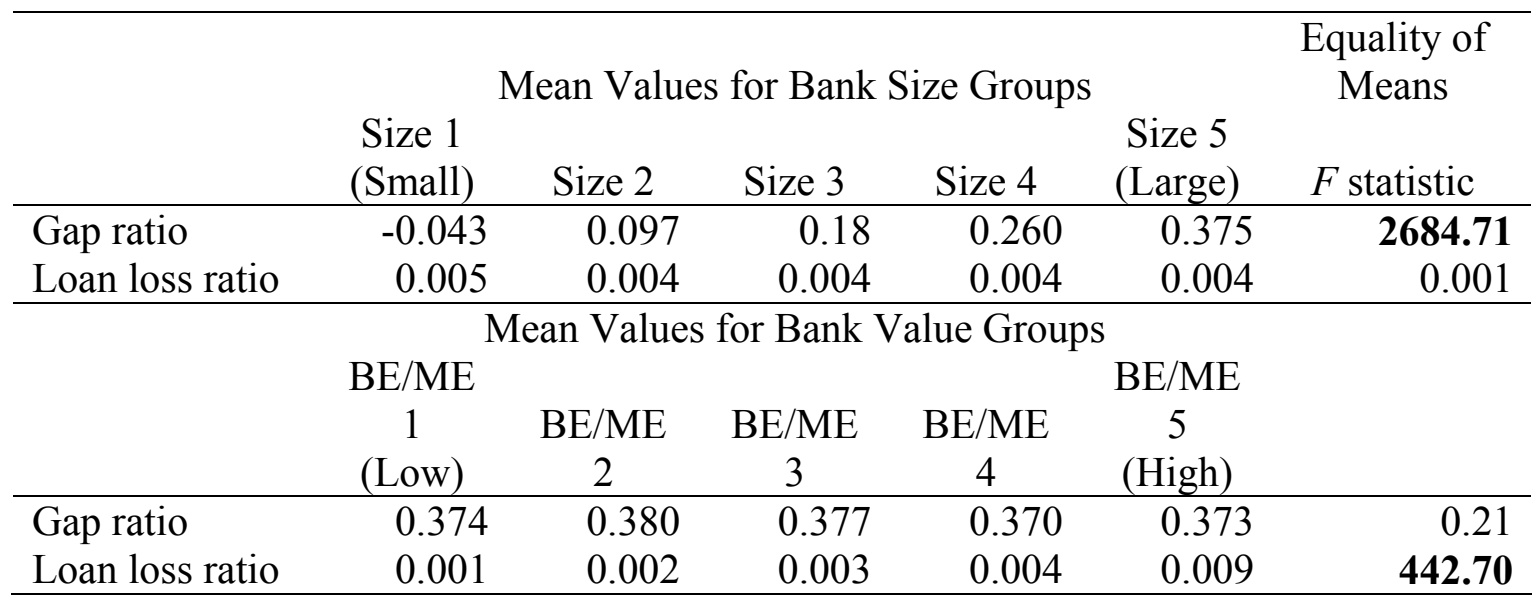

may reflect the monopolistic power that these banks have on the asset side of their balance sheets with respect to smaller banks with marginal or zero monopolistic power.

On a monthly basis, most shifts in the yield curve are due to changes in shortterm rather than long-term interest rates, most likely induced by shifts in the monetary policy bias. As short-term rates fall inducing positive shocks in the slope of the yield curve, the results suggest that the positive carry trade will dominate the negative effects due to an expected future recession for negatively gapped small banks, whereas for positively-gapped (larger) banks the last effect will be the dominant one. According to the banking literature, big banks with large charter values tend to be more risk-averse than small banks. This provides an economic explanation for the different risk exposures of small and big banks to shocks in TERM. 
The results have important consequences for the broad credit view of the monetary transmission channel that stresses the role of banks as capital providers. From this point of view, negative shocks in the slope of the yield curve, perhaps induced by a tightening bias in monetary policy, on one hand may crowd out small banks from the lending market as they will be forced to ration credit, and on the other hand, will allow big banks (with significant market power in the asset side of their balance sheets) to raise the effective cost of lending of those firms considered as risky, i.e., crowding out small firms from the borrowing market. The combination of these two effects most likely will trigger an economic slowdown in the small business sector. In this respect, there is empirical evidence that this is exactly what happened during the recession of 1990-1991 in the U.S. (e.g., see Kashyap and Stein (1995, 2000), and Kishan and Opiela (2000)).

\section{Robustness Checks}

\section{D.1. Estimation Bias}

As in Petkova (2006), I conduct a Monte Carlo experiment in order to assess the small sample properties of the time-series factor loadings and the cross-sectional risk premia, and determine the size and direction of the estimation bias. The Monte Carlo experiment is implemented as follows. First, the resulting betas and risk premia are assumed given. The null hypothesis is that the two-factor ICAPM model with $R_{M}^{e}$ and $\hat{u}_{\text {TERM }}$ is correct. Next, the finite sample distribution of the betas is established (assuming a standard normal deviate for the measurement error) bootstrapping 10,000 betas. Finally, the bootstrapped betas are used in cross-sectional regressions to get the sample distributions of the risk premia. Since only two risk factors were found to be priced in 


\section{Table VII}

\section{Bootstrap Simulation Analysis}

This table reports the Monte Carlo results. Initially, I draw 10,000 random betas assuming a standard normal distribution and using bootstrapped errors as a proxy for the measurement error in the regressions. Next, I obtain the finite distribution of the factor loadings in the first-stage time-series regressions and the finite distribution of the risk premia parameters in the second-stage cross-sectional regressions.

\begin{tabular}{lcccccc}
\hline & Null Hypothesis & \multicolumn{5}{c}{ Finite Sample Distribution } \\
& $H_{0}$ & $2.5 \%$ & $10 \%$ & $50 \%$ & $90 \%$ & $97.5 \%$ \\
\hline$\hat{\lambda}_{R_{M}^{e}}$ & 0.95 & 0.87 & 0.90 & 0.93 & 0.98 & 1.02 \\
$\lambda_{\hat{u}}$ & 0.79 & 0.33 & 0.51 & 0.73 & 1.02 & 1.24 \\
$\lambda_{R F}$ & -15.67 & -67.08 & -48.52 & -20.34 & 10.54 & 29.95 \\
$\hat{n}_{T E R M}$ & 4.14 & -3.02 & -0.62 & 2.48 & 6.05 & 8.90 \\
$\hat{\lambda}_{\hat{u}}$ & & & & & & \\
\hline
\end{tabular}

the cross-section of bank stock returns, Figure 1 only reports the finite distribution of the market and term spread betas.

The results confirm the robustness of the statistical significance of the betas and risk premia reported before. The market factor loading is unbiased. The small sample distribution of the factor loading for $\hat{u}_{\text {TERM }}$ exhibits a downward bias, so any potential EIV problem will bias the results toward less statistical significance (as in Panel A Table V). Table VII reports the small sample distribution of the risk premia parameters. Note that the small sample distributions of the risk premia corresponding to $R_{M}^{e}$ and $\hat{u}_{\text {TERM }}$ sensitivities are unbiased, and the $50 \%$ critical values are very close to the values under the null hypothesis that the model is correct. Hence, the hypothesis that $R_{M}^{e}$ and $\hat{u}_{\text {TERM }}$ risk premia are equal to zero can be rejected with a $95 \%$ confidence level. In brief, the two-factor ICAPM model passes this robustness check. 

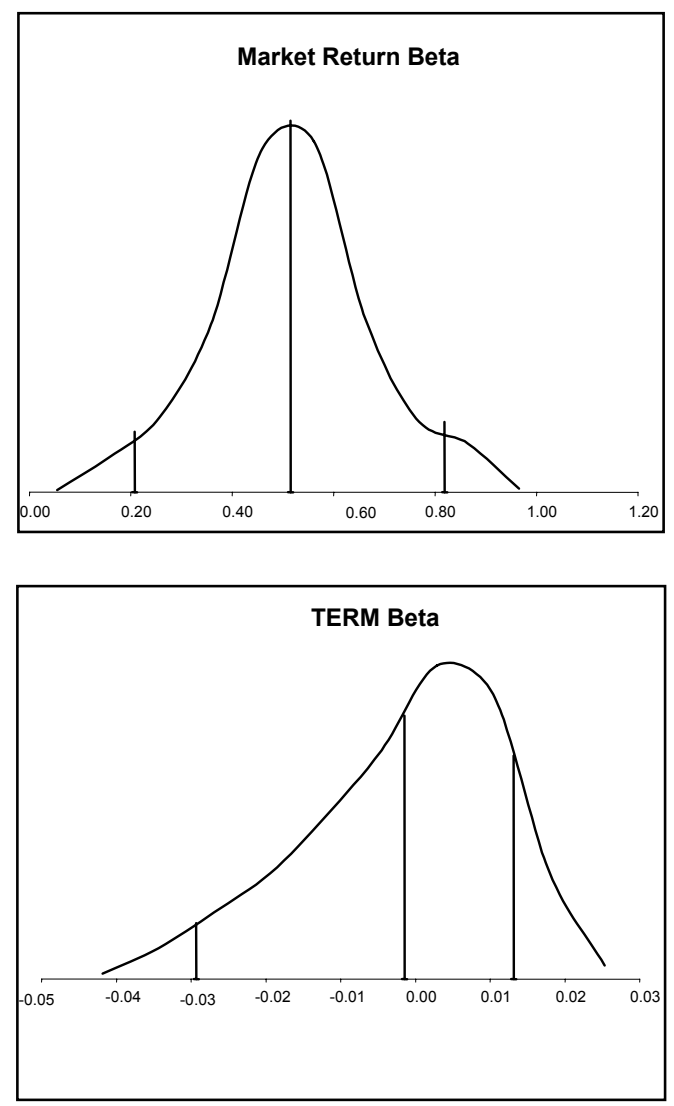

FIGURE 1.- Betas' Finite Sample Distributions. The null hypothesis is that the ICAPM model is correct. Then, the finite sample distribution of the betas is established (assuming a standard normal deviate as proxy for the measurement error) based on simulating 10,000 factor loadings. The bootstrapped betas are then used to estimate the factor risk premia in cross-section regressions. In this way the finite sample distributions of the risk premia are generated. 
Table VIII

Incremental Explanatory Power of the Fama-French Risk Factors

(Cross Section Regression: $\overline{\mathbf{R}-R}_{f}=\hat{\beta} \lambda+\boldsymbol{\alpha}$ )

This table examines whether size (ME), book-to-market (BE/ME), and momentum (UMD) add predictive power to a two-factor ICAPM model, which includes the market factor, $R_{M}^{e}$, and innovations in the term spread, $\hat{u}_{\text {TERM }}$.

Fama-Macbeth 1 Year Rolling Regressions $(N=194)$

\begin{tabular}{|c|c|c|c|c|c|}
\hline & $\begin{array}{c}\hat{\lambda} \\
{ }_{R}^{e} \\
{ }_{M} \\
\end{array}$ & $\lambda_{\hat{u}}{ }_{T E R M}$ & $\lambda_{\hat{u}}{ }_{S M B}$ & $\lambda_{\hat{u}}{ }_{H M L}$ & $\lambda_{\hat{u}}$ \\
\hline Estimate & $0.61 \%$ & $-10.68 \%$ & $-0.25 \%$ & & \\
\hline std. $t$-stat & 1.64 & -1.57 & -1.36 & & \\
\hline adj.t-stat & 1.50 & -1.43 & -1.25 & & \\
\hline Estimate & $0.63 \%$ & $-10.78 \%$ & $-0.23 \%$ & $0.14 \%$ & \\
\hline std. $t$-stat & 1.72 & -1.59 & -1.19 & 0.84 & \\
\hline adj.t-stat & 1.58 & -1.44 & -1.09 & 0.76 & \\
\hline Estimate & $0.71 \%$ & $-6.68 \%$ & $-0.13 \%$ & $0.07 \%$ & $-0.73 \%$ \\
\hline std. t-stat & 2.05 & -0.99 & -0.66 & 0.41 & -1.91 \\
\hline adj.t-stat & 1.88 & -0.90 & -0.61 & 0.37 & -1.72 \\
\hline
\end{tabular}

\section{D.2. Fama-French Factors}

Table VIII presents the results for a set of cross-sectional regressions adding the risk factors $S M B, H M L$, and $U M D$ to the two-factor ICAPM model. Size (BE) and bookto-market (BE/ME) do not add any explanatory power to the two-factor ICAPM model. However, $U M D$ appears to have (weak) incremental explanatory power with a $90 \%$ confidence level. Table IX reports the results on the contemporaneous relation between the Fama-French factors and $\hat{u}_{D I V}, \hat{u}_{R F}, \hat{u}_{T E R M}$, and $\hat{u}_{D E F}$. I run time-series regressions for each Fama-French factor including momentum. The $S M B$ factor covaries negatively and significantly with innovations in TERM. The $H M L$ factor covaries positively and significantly with innovations in dividend yields and the level of the interest rate. The $U M D$ factor covaries positively and significantly with innovations in TERM. These 
Table IX

\section{Relation Between Fama-French Factors and State Variables \\ (Regression: $\hat{u}_{t}=c_{0}+c_{1} \hat{u}_{D I V, t}+c_{2} \hat{u}_{R F, t}+c_{3} \hat{u}_{T E R M, t}+c_{4} \hat{u}_{D E F, t}+\varepsilon_{t}$ )}

This table presents time-series regressions $\hat{u}_{S M B}, \hat{u}_{H M L}$, and $\hat{u}_{U M D}$ on $\hat{u}_{D I V}, \hat{u}_{R F}, \hat{u}_{T E R M}$, and $\hat{u}_{D E F}$. The $t$-statistics are corrected for heteroskedasticity and autocorrelation using the (HAC) Newey-West estimator. Highlighted values denote statistical significance at the $5 \%$ level. The period is July 1986 to September 2003.

PANEL A: $S M B(\mathrm{ME})$

\begin{tabular}{lcccc}
\hline & Coefficient & Std. Error & t-Statistic & Prob. \\
\hline$\hat{\alpha}$ & -0.0108 & 0.0486 & -0.2225 & 0.8240 \\
$\hat{\beta}_{\hat{u}_{D I V}}$ & -0.0654 & 0.3109 & -0.2103 & 0.8335 \\
$\hat{\beta}_{\hat{u}_{R F}}$ & -0.3531 & 0.2630 & -1.3424 & 0.1802 \\
$\hat{\beta}_{\hat{u}}$ & & & & \\
$\quad{ }_{\text {TERM }}$ & -0.1106 & $\mathbf{0 . 0 4 9 9}$ & $\mathbf{- 2 . 2 1 6 3}$ & $\mathbf{0 . 0 2 7 2}$ \\
$\beta_{D E F}$ & 0.0408 & 0.0516 & 0.7898 & 0.4301 \\
\hline R-squared & 0.0358 & & & \\
Adjusted R-squared & 0.0166 & & & \\
\hline
\end{tabular}

PANEL B: $H M L$ (BE/ME)

\begin{tabular}{lcccc}
\hline & Coefficient & Std. Error & t-Statistic & Prob. \\
\hline$\hat{\alpha}$ & -0.0061 & 0.0225 & -0.2715 & 0.7862 \\
$\hat{\beta}_{\hat{u}_{D I V}}$ & 0.4160 & $\mathbf{0 . 1 4 4 2}$ & $\mathbf{2 . 8 8 5 4}$ & $\mathbf{0 . 0 0 4 1}$ \\
$\hat{\beta}_{\hat{u}_{R F}}$ & 0.2929 & $\mathbf{0 . 1 2 2 0}$ & $\mathbf{2 . 4 0 1 0}$ & $\mathbf{0 . 0 1 6 8}$ \\
$\hat{\beta}_{\hat{u}}$ & & & & \\
${ }_{T E R M}$ & -0.0121 & 0.0231 & -0.5214 & 0.6023 \\
$\beta_{\hat{u}_{D E F}}$ & -0.0306 & 0.0240 & -1.2800 & 0.2013 \\
\hline R-squared & 0.0588 & & & \\
Adjusted R-squared & 0.0401 & & &
\end{tabular}

PANEL C: UMD

\begin{tabular}{lcccc}
\hline & Coefficient & Std. Error & t-Statistic & Prob. \\
\hline$\hat{\alpha}$ & -0.0082 & 0.0656 & -0.1257 & 0.9001 \\
$\hat{\beta}_{\hat{u}_{D I V}}$ & -0.7095 & 0.5053 & -1.4042 & 0.1618 \\
$\hat{\beta}_{\hat{u}_{R F}}$ & -0.3018 & 0.5481 & -0.5507 & 0.5824 \\
$\hat{\beta}_{\hat{u}}$ & & & & \\
$\quad{ }_{\hat{u}_{D E R}}$ & 0.1740 & $\mathbf{0 . 0 8 7 9}$ & $\mathbf{1 . 9 7 8 8}$ & $\mathbf{0 . 0 4 9 2}$ \\
\hline R-squared & -0.0653 & 0.0740 & -0.8823 & 0.3787 \\
\hline Adjusted R-squared & 0.0427 & & & \\
\hline
\end{tabular}


results help to explain the (weak) incremental explanatory power of $U M D$ in crosssectional regressions and the (weak) predictive power of $H M L$ in time-series regressions. D.3. Conditional Tests of Long Run Predictability

The next step in the analysis seeks to show the out-of-sample predictive power that innovations in TERM and $D E F$ have as predictors of future investment opportunities (measured by the Sharpe ratio) as required by the ICAPM. The analysis also provides and assessment of any potential look-ahead bias. For this purpose, I perform univariate conditional tests, as defined in Polk et al. (2005). ${ }^{9}$ Consider the following one-period prediction model:

$$
\begin{aligned}
& y_{t}=\mu_{1}+\theta x_{t-1}+u_{t}, \\
& x_{t}=\mu_{2}+\rho x_{t-1}+v_{t},
\end{aligned}
$$

where $E\left[u_{t}\right]=E\left[v_{t}\right]=0, E\left[u_{t}^{2}\right]=\sigma_{1}^{2}, E\left[v_{t}^{2}\right]=\sigma_{2}^{2}, E\left[u_{t}, v_{t}\right]=\gamma$.

The goal is to test the null hypothesis $H_{0}: \theta=0 .{ }^{10}$ Table $\mathrm{X}$ presents the results for the post-WWII time period 1951-2003 and selected subperiods. The first panel forecasts the maximum Sharpe ratio with innovations in TERM, and the second panel with innovations in $D E F$. Conditional inference is based on $t$-statistics computed with Eicker-

\footnotetext{
${ }^{9}$ One straightforward method would have been to run a Granger causality test. The problem is the wellknown drawback of this method in the presence of feedback effects.

${ }^{10}$ If the residuals are normally distributed, then there is a function $k(\rho)$ such that under $H_{0}: \theta=0$, $\operatorname{Pr}[\hat{t}>k(\rho)]=\alpha$. However, this might be a poor approximation in small samples if $y_{t}$ is persistent. Moreover, $\hat{\rho}_{O L S}$ will lead to size distortions. Recently, Jansson and Moreira (2003) propose a solution to this problem, and Polk et al. (2005) provide a feasible implementation of their procedure by approximating the critical function using an artificial neural network (ANN).
} 
TABLE X

Univariate Predictors for the Maximum Sharpe Ratio

$$
\text { (Model: } \begin{gathered}
\left.\frac{R_{M K T, t}^{e}}{\sigma_{M}}=\mu_{1}+\theta x_{t-1}+u_{t} ; x_{t}=\mu_{2}+\rho x_{t-1}+v_{t}\right) \\
\left(E\left[u_{t}^{2}\right]=\sigma_{1}, E\left[v_{t}^{2}\right]=\sigma_{2}, E\left[u_{t}, v_{t}\right]=\gamma\right)
\end{gathered}
$$

This table presents univariate conditional tests as defined in Polk et al. (2005) to check the power of innovations on TERM and $D E F$ to predict changes in future investment opportunities measured by the Sharpe ratio. $t$-stat is the standard $t$-statistic for testing the null hypothesis $H_{0}: \hat{\theta}=0$. The confidence interval is a two-sided interval for $\theta$ correcting for heteroskedasticity. The p-value is computed using the uncorrected $t$-statistic and $\mathrm{p}^{\mathrm{W}}$-value using heteroskedastic-robust Eicker-Huber-White (HC0) $t$-statistics. The confidence interval is a robust-heteroskedastic 2-sided interval for $\theta$. Hatted variables are unrestricted OLS estimates.

\begin{tabular}{|c|c|c|c|c|c|c|c|}
\hline Specification & $\hat{\theta}$ & $\begin{array}{c}\text { t-stat } \\
\text { [p-value }] \\
{\left[\mathrm{p}^{\mathrm{w}} \text {-value }\right]}\end{array}$ & $\begin{array}{c}95 \% \text { confidence } \\
\text { interval }\end{array}$ & $\hat{\rho}$ & $\hat{\gamma}$ & $\hat{\sigma}_{1}$ & $\hat{\sigma}_{2}$ \\
\hline 1951:1-2003:12 & 0.3401 & $\begin{array}{c}2.030 \\
{[0.020]} \\
{[0.021]}\end{array}$ & {$[-1.686,1.632]$} & -0.0035 & 0.6200 & 1.2789 & 1.6766 \\
\hline 1951:1-1964:12 & 0.1780 & $\begin{array}{l}0.4760 \\
{[0.307]} \\
{[0.312]}\end{array}$ & {$[-1.680,1.642]$} & -0.0472 & -0.0023 & 0.7885 & 0.1698 \\
\hline 1965:1-1985:12 & 0.5530 & $\begin{array}{c}2.978 \\
{[0.000]} \\
{[0.002]}\end{array}$ & {$[-1.634,1.682]$} & -0.0050 & 0.0644 & 1.0181 & 0.4293 \\
\hline 1986:1-2003:12 & -0.7390 & $\begin{array}{l}-1.875 \\
{[0.975]} \\
{[0.067]}\end{array}$ & {$[-1.673,1.645]$} & 0.1477 & -0.1013 & 1.0793 & 0.1967 \\
\hline
\end{tabular}

PANEL A: Prediction by $\hat{u}$

\begin{tabular}{|c|c|c|c|c|c|c|c|}
\hline Specification & $\hat{\theta}$ & $\begin{array}{c}\mathrm{t} \text {-stat } \\
{[\mathrm{p} \text {-value }]} \\
{\left[\mathrm{p}^{\mathrm{w}} \text {-value }\right]}\end{array}$ & $\begin{array}{l}95 \% \text { confidence } \\
\text { interval }\end{array}$ & $\hat{\rho}$ & $\hat{\gamma}$ & $\hat{\sigma}_{1}$ & $\hat{\sigma}_{2}$ \\
\hline 1951:1-2003:12 & 0.1091 & $\begin{array}{c}0.550 \\
{[0.316]} \\
{[0.286]}\end{array}$ & {$[-1.679,1.639]$} & -0.0036 & 0.5653 & 1.2829 & 0.4526 \\
\hline 1951:1-1964:12 & 0.2793 & $\begin{array}{c}0.495 \\
{[0.312]} \\
{[0.319]}\end{array}$ & {$[-1.643,1.680]$} & -0.0412 & 0.0064 & 0.7885 & 0.1132 \\
\hline 1965:1-1985:12 & 0.1297 & $\begin{array}{c}0.443 \\
{[0.326]} \\
{[0.337]}\end{array}$ & {$[-1.638,1.678]$} & 0.0178 & 0.1084 & 1.0449 & 0.2424 \\
\hline 1986:1-2003:12 & -0.0194 & $\begin{array}{l}-0.069 \\
{[0.515]} \\
{[0.517]}\end{array}$ & {$[-1.638,1.678]$} & -0.0968 & -0.0159 & 1.0892 & 0.2436 \\
\hline
\end{tabular}

PANEL B: Prediction by $\hat{u}$ 
Huber-White (HC0) standard errors. ${ }^{11}$

The results reveal that innovations in TERM do help to forecast future investment opportunities measured by the Sharpe ratio. For all the periods except 1951-1964, I am able to reject the null hypothesis at a 5\% significance level. I cannot reject the null hypothesis for the case of innovations to $D E F$ at any period of time. The last result supports the common knowledge that the relevance of $D E F$ transcends investors' intertemporal concerns due to real business cycle effects. Importantly, the results also show that expected excess market returns are predictable, e.g., for the sample period 1986-2003 there is negative serial correlation between innovations in current returns and revisions in expected future returns. Moreover, the results show that the sign of this correlation varies through time, which suggests that risk premia might be time varying. This finding is in line with a large and growing body of empirical work (see e.g., Campbell and Shiller (1988), Fama and French (1989), and Lettau and Ludvigson (2001)). In this case, the SDF will be a state-dependent function of the state variables, and inference through unconditional moments is problematic.

\footnotetext{
${ }^{11}$ Monte Carlo experiments suggest that this $t$-statistic is much more robust to heteroskedasticity than the uncorrected $t$-statistics. The Eicker-Huber-White (HC0) estimator is equal to $\left(X^{\prime} X\right)^{-1} X^{\prime} \Phi X\left(X^{\prime} X\right)^{-1}$ where $\Phi=\operatorname{diag}\left[u_{t}^{2}\right]$ and $u_{t}^{2}=\left(u_{t}-0\right) / u_{t}^{2}$. Although this estimator is consistent in the presence of heteroskedasticity of unknown form, it has poor small sample properties.
} 
D.4. Other Conditional Tests ${ }^{12}$

According to Ferson and Harvey (1999), a state-dependent SDF can be specified introducing interacting scale factors (i.e., instruments) that might be important to explain time variation in returns' moments. The goal is to provide a specification test of the unconditional model augmenting the sample of testing portfolios.

For this purpose I estimate a scaled version of the ICAPM in SDF form using a general method of moments (GMM) procedure. GMM in SDF form is equivalent to a cross-sectional regression of mean excess returns on the second moments of the factors' returns (see Cochrane (2005, p. 256-259)). The set of instrumental variables included are those that show predictive power in the time-series regressions lagged one period, i.e., $R_{M, t-1}^{e}, \hat{u}_{H M L, t-1}, \hat{u}_{T E R M, t-1}, \hat{u}_{D E F, t-1}$, and the constant $c$. This procedure has the following intuitive interpretation: the scaled returns come from managed portfolios of bank stocks in which the manager invests more or less according to the signal provided by the instrument. $^{13}$

Table XI reports the results. The $t$-statistics corrected for heteroskedasticity and serial correlation using Newey-West HAC estimator show that MKT, TERM, and DEF factors are priced in a conditional (C) ICAPM model. The fact that the risk premium in

\footnotetext{
${ }^{12}$ I use portfolios $11,15,23,25,33,35,43,45,53$, and 55. With all 25 portfolios I would have a large number of moment conditions in 208 data points. The iterated GMM estimates behave badly with large covariance matrices.

${ }^{13}$ Of course, the usual instrument selection problem remains. This is the well-known Hansen and Richard's (1987) critique. Investors may observe finer information sets than the econometrician. This fact potentially reduces the power of the tests performed on the scaled returns. However, omitting instruments does not bias the tests' results. A conditional asset pricing model with respect to a finer information set does not imply a conditional asset pricing model with respect to a coarser information set, as it does not imply an unconditional factor model.
} 
Table XI

\section{Cross-Section Tests in SDF Form - GMM Estimation Procedure - (Moment Condition: $E_{T}\left(\mathbf{R}^{\mathrm{e}}-\left(\mathbf{R}^{\mathrm{e}} \widetilde{\mathbf{f}}^{\prime}\right) \times \mathbf{b}\right)=0$ )}

This table presents GMM regressions in SDF form using excess returns on 10 portfolios sorted by size (ME) and book-to-market (BE/ME). It shows the results for a scaled ICAPM model, which includes, $R_{M}^{e}$, $\hat{u}_{R F}, \hat{u}_{T E R M}$, and $\hat{u}_{D E F}$ as risk factors. The estimation procedure corrects for heteroskedasticity and serial correlation using Newey-West HAC estimator. The parsimonious set of instrumental variables includes those variables that show predictive power in time-series regressions lagged one period, i.e., $R_{M, t-1}^{e}, \hat{u}_{H M L, t-1}, \hat{u}_{T E R M, t-1}, \hat{u}_{D E F, t-1}$, and $c$. The risk premium shown in $\%$ terms is $\lambda=-r \times \operatorname{cov}\left(\widetilde{\mathbf{f}}, \widetilde{\mathbf{f}}^{\prime}\right) \times \mathbf{b}$. The table covers the period July 1986 - September 2003.

Three-Factor (C)ICAPM Model

\begin{tabular}{|c|c|c|c|c|}
\hline & Coefficient & Std. Error & t-Statistic & Prob. \\
\hline$\hat{b}_{R M}$ & 12.7447 & 2.8887 & 4.4118 & 0.0000 \\
\hline$\hat{\lambda}_{R M}$ & 1.46 & & & \\
\hline$\hat{b}_{\hat{u}}$ & 0.3404 & 0.6014 & 0.5660 & 0.5715 \\
\hline$\lambda_{\hat{u}}$ & 0.01 & & & \\
\hline$\hat{b}_{\hat{u}}$ & -0.2545 & 0.1144 & -2.2245 & 0.0262 \\
\hline$\hat{\lambda}_{\hat{u}}$ & -25.16 & & & \\
\hline$\hat{b}_{\hat{u}}$ & -0.3197 & 0.1280 & -2.4966 & 0.0126 \\
\hline$\hat{\lambda}_{\hat{u}}$ & -8.70 & & & \\
\hline $\begin{array}{l}\text { Hansen J-Test } \\
\text { Probability }\end{array}$ & $\begin{array}{l}0.2378 \\
62.57 \%\end{array}$ & & & \\
\hline
\end{tabular}

default has negative sign seems to support the argument in Grenadier and Hall (1995)

that capital requirement regulations induced by Basel I in the late eighties shifted the risk in banks away from default and into term. Additionally, the unconditional model passes

the specification test, as the excess market return and innovations on the term spread remain statistically significant in the augmented sample of scaled test portfolios using a different estimation approach. 


\section{F. Explanatory Power of TERM and DEF}

Table XII reports the contemporaneous relation between bank specific accounting risk factors and stock return sensitivities to $\hat{u}_{T E R M}$ and $\hat{u}_{D E F}$. In this regard, Flannery and Sorescu (1996) have found that yield spreads on bank holding company debentures are sensitive to the banks' interest rate gap and loan loss ratios. In view of their work, as already mentioned, I constructed similar bank-specific financial ratios measuring short-term gap and loan loss ratios for individual banks. ${ }^{14}$ I use these accounting measures to construct zero-investment mimicking portfolios denoted GAP (i.e., small minus big interest rate gap) and $L O A N$ (i.e., high minus low loan losses). $G A P$ is constructed as the monthly difference between the simple average of returns on the three small-gap portfolios (S2/L2, S2/M2, and S2/H2) and the simple average of the returns on the three big-gap portfolios (B2/L2, $\mathrm{B} 2 / \mathrm{M} 2$, and $\mathrm{B} 2 / \mathrm{H} 2) . L O A N$ is constructed as the monthly difference between the simple average of the returns on the two highloan-loss portfolios $(\mathrm{S} 2 / \mathrm{H} 2$ and $\mathrm{B} 2 / \mathrm{H} 2)$ and the simple average of the returns on the two low-loan-loss portfolios (S2/L2 and B2/L2).

As shown in Table XII, there is a statistically significant correlation between bank stock return sensitivities to $\hat{u}_{T E R M}$ and GAP, and between bank stock return sensitivities to $\hat{u}_{D E F}$ and $L O A N$. This is consistent with the observed fact that banks have gap and loan loss ratios, which differ systematically across size groups as evidenced in Table VI (viz., gap and loan loss ratios increase with size). Hence, innovations in TERM

\footnotetext{
${ }^{14}$ Short-term gap is defined as before. Loan losses equal net charge-offs for losses on loans (i.e., gross charge-offs minus recoveries) divided by the amount of total loans.
} 
Table XII

Contemporaneous Correlation Between TERM, DEF, GAP, and $L O A N$

This table presents correlations between the bank specific risk factors GAP and $L O A N$ and stock return sensitivities to innovations in $\hat{u}_{T E R M}$, and $\hat{u}_{D E F}$.

PANEL A: Between GAP \& BetaTERM

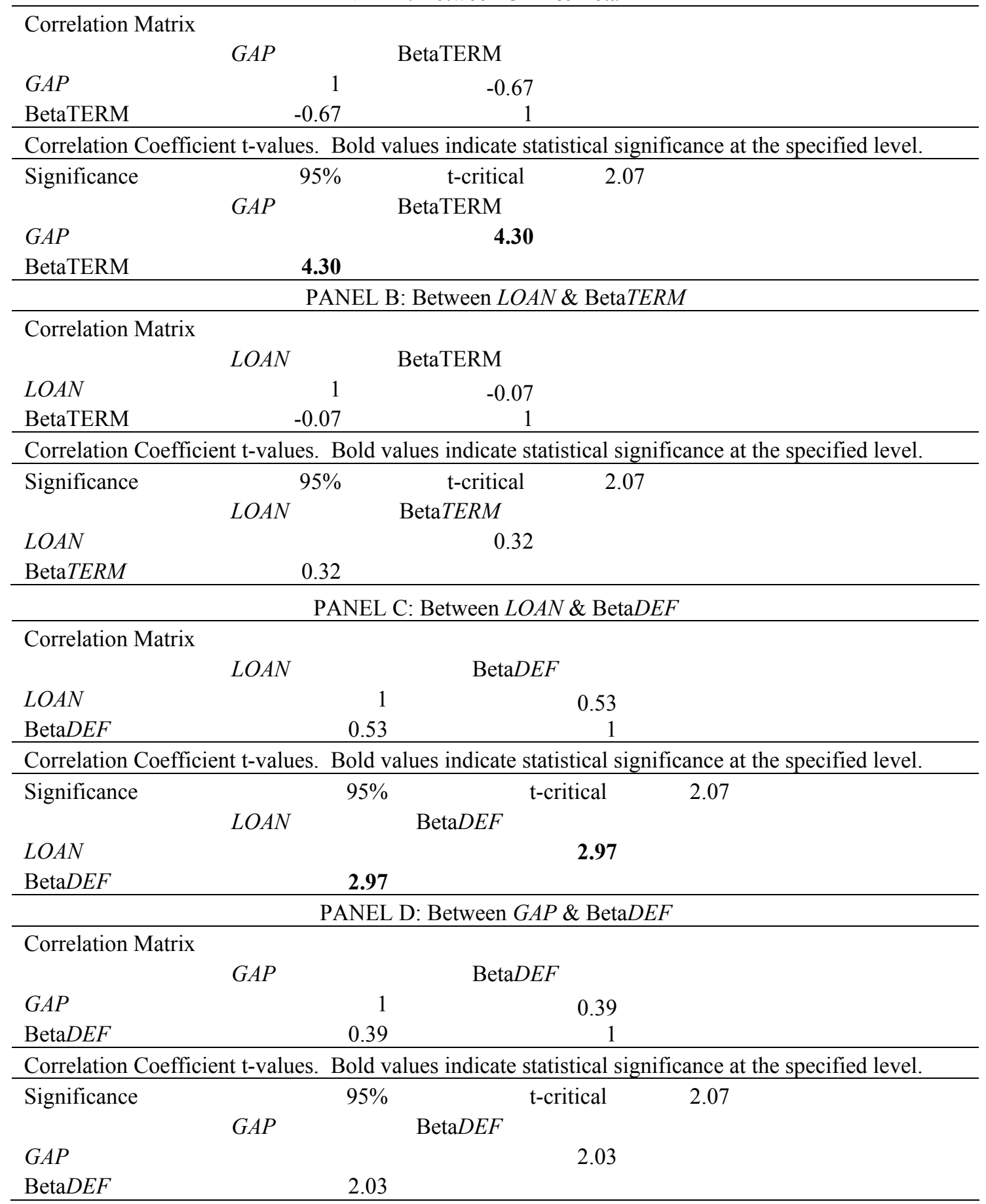


and $D E F$ capture bank-specific information related to interest rate and loan credit risks.

Importantly, the empirical results in this section suggest that banks are not characteristically opaque with respect to non-financial stocks, in the sense that outsiders can learn the risk profile of banks using publicly available market information. As such, indirect market-based discipline under Basel II appears to be a feasible-incentive mechanism to enhance bank supervision. 


\section{CONCLUSION}

This dissertation attempts to identify an appropriate empirical asset-pricing model for commercial bank stocks. Alternative asset pricing models are tested, including those that have been used to explain the returns of nonfinancial stocks, i.e., the singlefactor CAPM, three-factor Fama-French model, and ICAPM. The empirical results indicate that an unconditional two-factor ICAPM model that includes a market factor and shocks to the slope of the yield curve is useful in explaining the cross section of bank stock returns. I also provide evidence that shocks to the default spread are priced in a conditional version of the two-factor ICAPM model.

The results have a number of practical implications. For example, the characterization of the risk profile of banks in terms of two observable macro-variables namely, the stock market and the yield curve - has important implications for bank regulators seeking to foster stability in the banking industry via market discipline. Although our evidence rejects the hypothesis that investors cannot rationally differentiate among the risks undertaken by the major U.S. banks, we cannot conclude that self-regulatory market discipline can effectively control banking firms. My view is that market discipline constitutes an efficient instrument to enhance banks supervision by regulators. The results also suggest that event studies in the banking industry should employ a two-factor model that includes market and term variables. Finally, the twofactor banking model could be used to compute the cost of capital for banking institutions. In this respect, by correctly assessing the banks' cost of equity, the role of banks in the monetary transmission mechanism can be efficiently assessed. 


\section{REFERENCES}

Akella, Srinivas, and Stuart Greenbaum, 1992, Innovations in interest rates, duration transformation, and bank stock returns, Journal of Money, Credit and Banking, 24, 27-42.

Bae, Sung, 1990, Interest rate changes and common stock returns of financial institutions: Revisited, Journal of Financial Research, 13, 71-79.

Baltagi, Badi, Susan Garvin, and Steven Kerman, 1989, Further Monte Carlo evidence on seemingly unrelated regressions with unequal number of observations, Annales D'èconomie Et De Statistique, 14, 103-115.

Barber, Brad, and John Lyon 1997, Firm size, book-to-market ratio, and security returns: A holdout sample of financial firms, Journal of Finance, 52, 875-883.

Benink, Harald, and Christian Wolff, 2000, Survey data and the interest rate sensitivity of U.S. bank stock returns, Economic Notes, 29, 201-213.

Bolton, Patrick, and Xavier Freixas, 2006, Corporate finance and the monetary transmission mechanism, Review of Financial Studies, 19, 829-870.

Brennan, Michael, Ashley Wang, and Yihong Xia, 2004, Estimation and test of a simple model of intertemporal capital asset pricing, Journal of Finance, 54, 1553-1608.

Campbell, John, 1987, Stock returns and the term structure, Journal of Financial Economics, 18, 373-399.

Campbell, John, 1993, Intertemporal asset pricing without consumption data, American Economic Review, 83, 487-512. 
Campbell, John, 1996, Understanding risk and return, Journal of Political Economy, 104, 298-345.

Campbell, John, and Robert Shiller, 1988, Stock prices, earnings, and expected dividends, Journal of Finance, 43, 661-676.

Campbell, John, and Tuomo Vuolteenaho, 2004, Bad beta, good beta, American Economic Review, 94, 1249-1275.

Chen, Joseph, 2003, Intertemporal CAPM and the cross-section of stock returns, Working paper, University of Southern California.

Choi, Jongmoo, Elyas Elyasiani, and Kenneth Kopecky, 1992, The sensitivity of bank stock returns to market, interest and exchange rate risks, Journal of Banking and Finance, 16, 983-1004.

Cochrane, John, 2005, Asset Pricing, Princeton University Press, Princeton, New Jersey. Dinenis, Elias, and Sotiris Staikouras, 1998, Interest rate changes and common stock returns of financial institutions: Evidence from the U.K., European Journal of Finance, 4, 113-127.

Elyasiani, Elyas, and Iqbal Mansur, 1998, Sensitivity of the bank stock returns distribution to changes in the level and volatility of interest rate: A GARCH-M model, Journal of Banking and Finance, 22, 535-563.

Fama, Eugene, and James MacBeth, 1973, Risk, return, and equilibrium: Empirical tests, Journal of Political Economy, 81, 607-636.

Fama, Eugene, and Kenneth French, 1989, Business conditions and expected returns on stocks and bonds, Journal of Financial Economics, 25, 23-49. 
Fama, Eugene, and Kenneth French, 1992, The cross-section of expected returns, Journal of Finance, 47, 427-465.

Fama, Eugene, and Kenneth French, 1993, Common risk factors in the returns on stocks and bonds, Journal of Financial Economics, 33, 3-56.

Fama, Eugene, and Kenneth French, 1996, The CAPM is wanted, dead or alive, Journal of Finance, 51, 1947-1958.

Fama, Eugene, and Kenneth French, 1998, Value versus growth: The international evidence, Journal of Finance, 53, 1975-1999.

Ferson, Wayne, and Campbell Harvey, 1999, Conditioning variables and the crosssection of stock returns, Journal of Finance, 54, 1325-1360.

Flannery, Mark, 1981, Market interest rates and commercial bank profitability: An empirical investigation, Journal of Finance, 36, 1085-1101.

Flannery, Mark, and Christopher James, 1984, The effect of interest rate changes on the common stock returns of financial institutions, Journal of Finance, 39, 1141-1153.

Flannery, Mark, and Sorin Sorescu, 1996, Evidence of bank market discipline in subordinated debenture yields: 1983-1991, Journal of Finance, 51, 1347-1377.

Flannery, Mark, Allaudeen Hameed, and Richard Harjes, 1997, Asset pricing, timevarying risk premia and interest rate risk, Journal of Banking and Finance, 21, 31535.

Flannery, Mark, Simon Kwan, and Mahendrarajah Nimalendran, 2002, Market evidence on the opaqueness of banking firm assets, Working Paper, University of Florida and Federal Reserve of San Francisco. 
Fogler, Russell, John Kose, and James Tipton, 1981, Three factors, interest rate differentials and stock groups, Journal of Finance, 36, 323-335.

Gibbons, Michael, Stephen Ross, and Jay Shanken, 1989, A test of the efficiency of a given portfolio, Econometrica, 57, 1121-1152.

Giliberto, Michael, 1985, Interest rate sensitivity in the common stocks of financial intermediaries: A methodological note, Journal of Financial and Quantitative Analysis, 20, 123-126.

Grenadier, Steven, and Brian Hall, 1995, Risk-based capital standards and the riskiness of bank portfolios: Credit and factor risks, Working paper, NBER, Cambridge, MA.

Guo, Hui, 2006, Time-varying risk premia and the cross-section of stock returns, Journal of Banking and Finance, 30, 2087-2107.

Hansen, Lars, and Scott Richard, 1987, The role of conditioning information in deducing testable restrictions implied by dynamic asset pricing models, Econometrica, 55, $587-614$.

Hanweck, Gerald, and Lisa Ryu, 2005, The sensitivity of bank net interest margins and profitability to credit, interest rate, and term-structure shocks across bank product specializations, FDIC Working paper series, George Mason University, and Federal Insurance Corporation.

Hodrick, Robert, David Ng, and Paul Sengmueller, 1999, An international dynamic asset pricing model, International Taxation and Public Finance, 6, 597-620.

Inoue, Atsushi, and Lutz Killian, 2002, In sample or out of sample tests of predictability: Which one should we use? Working paper, University of Michigan. 
Jagannathan, Ravi, and Zhenyu Wang, 1998, Asymptotic theory for estimating beta pricing models using cross-sectional regressions, Journal of Finance, 53, 1285-1309.

Jansson, Michael, and Marcelo Moreira, 2003, Conditional inference in models with nearly nonstationary regressors, Working Paper, Harvard University.

Jegadeesh, Narasimhan, 1990, Evidence of predictable behavior of security returns, Journal of Finance, 45, 881-898.

Jegadeesh, Narasimhan, and Sheridan Titman, 1993, Returns to buying winners and selling losers: Implications for stock market efficiency, Journal of Finance, 48, 6591.

Kashyap, Anil, and Jeremy Stein, 1995, The impact of monetary policy on bank balance sheets, Carnegie-Rochester Conference Series on Public Policy, 42, 151-195.

Kashyap, Anil, and Jeremy Stein, 2000, What do a million observations on banks say about the transmission of monetary policy? American Economic Review, 90, $407-$ 428.

Kishan, Ruby, and Timothy Opiela, 2000, Bank size, bank capital, and the bank lending channel, Journal of Money, Credit, and Banking, 32, 121-141.

Kothari, S. P., Jay Shanken, and Richard Sloan, 1995, Another look at the cross-section of expected stock returns, Journal of Finance, 50, 185-224.

Lakonishok, Josef, Andrei Shleifer, and Robert Vishny, 1994, Contrarian investment extrapolation and risk, Journal of Finance, 49, 1541-1578. 
Lettau, Martin, and Sidney Ludvigson, 2001, Resurrecting the (C) CAPM: A crosssectional test when risk premia are time-varying, Journal of Political Economy, 109, 1238-1287.

Li, Y., 1997, Intertemporal asset pricing without consumption data: Empirical tests, Journal of Financial Research, 20, 53-69.

Lynge, Jr., Morgan, and Kenton Zumwalt, 1980, An empirical study of the interest rate sensitivity of commercial bank returns: A multi-index approach, Journal of

Financial and Quantitative Analysis, 15, 731-742.

MacKinlay, Craig, 1995, Distinguishing among asset pricing theories: An ex ante analysis, Journal of Financial Economics, 35, 3-28.

Merton, Robert, 1973, An intertemporal capital asset pricing model, Econometrica, 41, $867-887$.

Pagan, Adrian, 1984, Econometric issues in the analysis of regressions with generated regressors, International Economic Review, 25, 221-247.

Petkova, Ralitsa, 2006, Do the Fama-French factors proxy for innovations in predictive variables? Journal of Finance, 61, 581-612.

Polk, Cristopher, Samuel Thompson, and Tuomo Vuolteenaho, 2005, Cross-sectional forecasts of the equity premium, Working paper, Northwestern University, and Harvard University.

Shanken, Jay, 1992, On the estimation of beta pricing models, Review of Financial Studies, 5, 1-34. 
Staikouras, Sotiris, 2003, The interest rate risk exposure of financial intermediaries: A review of the theory and empirical evidence, Financial Markets, Institutions and Instruments, 12, 257-289.

Stone, Bernell, 1974, Systematic interest-rate risk in a two-index model of returns, Journal of Financial and Quantitative Analysis, 9, 709-721.

Valkanov, Rossen, 2003, Long-horizon regressions: Theoretical results and applications, Journal of Financial Economics, 68, 201-232.

Yourougou, Pierre, 1990, Interest-rate risk and the pricing of depository financial intermediary common stock, Journal of Banking and Finance, 14, 803-20. 


\section{VITA}

NAME:

ADDRESS:

EMAIL ADDRESS:

EDUCATION:
Ariel Marcelo Viale.

Department of Finance, Barry Kaye School of Finance, Insurance, and Economics, Florida Atlantic University, 777 Glades Rd., Boca Raton, FL, 33431.

ariel@viale.net

B.A., Economics, Universidad Católica Andres Bello (UCAB), 1987.

M.S., Finance, Texas A\&M University, 2002.

Ph.D., Finance, Texas A\&M University, 2007. 